\title{
1. Citizen Engagement Challenges in Urban Disaster Management Programs with Special Reference to Fire, Waterlogging and Pandemics: Case of Bangladesh
}

\author{
Kazi Nazmul Huda ${ }^{*}$ M. Jamir Uddin ${ }^{2} \&$ Moslehuddin Chowdhury Khaled ${ }^{3}$ \\ ${ }^{1}$ Associate Professor, Dept. of Business Administration, Southern University Bangladesh, Chittagong, Bangladesh \\ ${ }^{2}$ Assistant Professor, Dept. of General Education, Southern University Bangladesh, Chittagong, Bangladesh \\ ${ }^{3}$ Associate Professor, Dept. of HRM \& General Management, Chittagong Independent University, Chittagong, Bangladesh \\ *Corresponding author: knhuda@yahoo.com/ \\ https://riiopenjournals.com/index.php/society sustainability/index
}

Doi: https://doi.org/10.38157/society_sustainability.v2i1.101

Citation: Huda, K.N., Uddin, M.J. \& Khaled, M.C. (2020). Citizen Engagement Challenges in Urban Disaster Management Programs with Special Reference to Fire, Waterlogging, and Pandemics: Case of Bangladesh, Society \& Sustainability, 2(1), 6174. Doi: https://doi.org/10.38157/society_sustainability.v2i1.101

\section{Research Article}

\begin{abstract}
The main objective of this study is to explore the challenges of engaging citizens in urban disaster management (UDM) in the urban fire, waterlogging, and pandemic like COVID 19. A qualitative research approach, mainly in-depth interview method was applied to gain insights from different government officials of civil defense, police force, and ward councilors of Dhaka and Chattogram City Corporations, who were experienced in working at the field level UDM. The study tried to investigate the challenges faced by the officials during disaster rescue operations with special reference to the role of urban citizens. The findings of the study capture, in detail, the challenges faced by different personnel involved in UDM operations. While citizen engagement is expected to be a positive notion, in most cases, citizens themselves become the main obstacle of disaster management, due to their ignorance, negligence, and lack of patience in the given disastrous and pandemic situation, and thus, hinders UDM operations and crisis management. The lessons learned from contemporary urban disasters like fire and the COVID 19 pandemic are recorded elaborately. Based on that, different recommendations are made to ensure the active engagement of citizens to facilitate UDM activities in an orderly manner.
\end{abstract}

Keywords: Urban Disaster Management, Citizen Engagement, Pandemic, COVID 19, Waterlogging, Bangladesh

\section{Introduction}

Though disaster is a natural calamity in almost all cases, the human being is mainly responsible for it (Asian Development Bank, 2008). In most cases, it occurs suddenly and severely damages 
human life. According to the United Nations International Strategy for Disaster Reduction (2009), any form of disaster seriously disrupts the function of economic and social life by damaging the life and economic resources. It creates a long term impact on the smooth functioning of an affected area, country, even a complete region. It breaks the usual routine of human life and creates anarchy in society. Disasters could be classified as natural disasters, manmade disasters, and complex disasters (Shaluf, 2007). Every natural disaster keeps its footprint on earth with its catastrophic destruction. The natural disasters namely earthquake, thunder strike, tsunami, or flash floods occurs without a warning. Through disaster management principles the risk level of disasters can be reduced proactively.

The term "disaster management" encompasses the complete realm of disaster-related activities. Traditionally, disaster management was considered as post-disaster actions conducted by relief and reconstruction of officials; yet disaster management covers a much broader scope, and many modern disaster managers may find themselves far more involved in pre-disaster activities than in post-disaster responses.

Bangladesh is a densely populated country in South East Asia and is very prone to different types of disasters. Many forms of natural disasters like cyclones, earthquakes, soil erosion, floods, and landslides are common in this delta. All these disasters affect the sustainable development of the country. The geophysical location of Bangladesh, its characteristics, the multiplicity of rivers, and the monsoon climate made this country highly vulnerable to natural disasters (Khan\& Rahman, 2007). Climate change adds a new dimension of disasters risk and vulnerability. Urban areas of Bangladesh are mostly prone to manmade disasters. Major divisional cities of the country are densely populated and the increasing level of urbanization creates disasters like floods and many social disasters like drug abdication, eve-teasing, rape, etc. The government and its different agencies and stakeholders are taking different policy measures but the degrees of such disasters are racing with the time.

According to Pandey \& Okazaki (2005), and Victoria (2003) participation of people in encountering disaster is an effective, proactive, and popular approach to disaster management. Disaster prone countries like Japan and the USA are getting the fruits of citizen engagement in managing all forms of disaster. Every disaster irrespective of its types and nature demands the participation of people. It is an effective way to mitigate the risk of disasters and manage a postdisaster activity. Engaging citizens in disaster management programs in Bangladesh has become an essential and urgent issue. To reduce the losses of disaster, minimizing the risks, and restoring the post-disaster situation an integrated policy framework must be developed to ensure citizen engagement in disaster management activities. The involvement of a vulnerable portion of our population, i.e. women, children, disabled persons, senior citizens is highly important to the participatory minimization of disaster risk and response. The empowerment of this vulnerable population renders the achievement of sustainability in disasters.

Urban Disaster is rising geometrically and its impact is higher than the disaster in the rural areas (Shaw, Surjan \& Parvin, 2016). Fifty percent of the world population are city dwellers and it will be near to seventy percent by the year 2050 (U.N. Department of Economic \& Social Affair, 2018). Therefore, the participation of the local citizen in managing disasters should be arranged in a 
meaningful way (Neubauer et al., 2013) to prevent and respond to disasters. Citizens must be provided with defined roles and responsibilities for disaster preparedness and disaster response to bring discipline in disaster management activities. However, for the lack of effective citizen engagement management, disaster management by the formal agencies becomes difficult at the time of disaster. The study will try to find the answers on how citizen engagement could be maximized at the time of disaster and what are the related challenges involved in this framework

\section{Statement of the Problem}

Urban disaster is extremely vulnerable as the cities are dense with population and highly compacted with concerts (Montoya, 2002). The major cities of Bangladesh are not free from high disaster risk. Among all, water-logging is a regular phenomenon relates to drainage congestion that mostly created for the negligence in residential waste disposal of the city dwellers. City corporations mostly failed to overcome this problem. This water logging problem is creating multiple waterborne diseases during rainy seasons. In recent times dengue fever is seen as an epidemic in Dhaka city and appeared as an outbreak all over Bangladesh. All the major cities of the country are vulnerable to fire hazards especially the industrial areas are mostly fire-prone due to lack of proper fire management system and installation of fire extinguisher equipment. A number of incidents are experienced in recent times and the catastrophes like Rana Plaza, Tazreen Garments many others are worth mentioning.

Ongoing worldwide pandemic; COVID-19 is a new experience in the history of the present millennium and is pulling the calm survival of human sepsis towards a Stone Age if it is not restrained the threat collectively. The coronavirus has triggered an unprecedented crisis in the history of mankind and the sheared scale is unpleasant and uncontrollable. People across the world have been suffering and the cases of death are rising at a geometric scale. Bangladesh is not being spared from this outbreak. To contain such threats mentioned above, necessary moves to be made by disaster management organizations to minimize the hazards of manmade disasters and engage citizens in disaster management activities in an orderly manner.

However, the harsh reality of all these disasters lies in the peoples' factor of disaster. It is human who brought this anathema by themselves. So, it is we who are to be accused of bringing the entire catastrophe in our life. Therefore, citizens should be trained and made conscious of preparing for a disaster, ways to prevent it, and the procedure to act at the time of disaster (Mathbor, 2007). This study will try to propose an outline of how to institutionalize the concept of citizen engagement in UDM programs in Bangladesh. The outcome of this research may help the policymakers and the practitioners to formulate citizen inclusive guideline to make the UDM program an effective one.

\section{Research Objectives}

The main objective of the study is to explore the necessity and degree of citizen engagement as a resilient intervention of the UDM program of Bangladesh. To attain the main objective, the following specific objectives are drawn:

- To explore the discipline of disaster management regarding the concept of citizen engagement. 
- To identify the extent of disengagement of the citizen in UDM activities.

- To ascertain the factors impeding effective citizen engagement in the UDM activities of Bangladesh.

- To provide policy direction to facilitate citizen engagement.

\section{Review of Literature}

\subsection{Disaster}

Disaster is a state of physical, mental, and social crises of human life (Oliver-Smith, 1999; KrollSmith, Couch \& Couch, 1991). It could be classified into natural, social, chemical, and social. Though it is always threatening to our life, the human being is the root cause of all forms of disasters occurring across the world. Every country across the world is prone to different forms of disasters. The consequence of every disaster keeps a footprint on mental trauma in human life (Quarantelli, 1985). Disasters are huge inflexible and unpredictable problems that challenge the highest resistance of mankind and ends with the loss of life, infrastructure, and paralyzing the economic condition of a country (Altay \& Green III, 2006).

Disaster in any form is a life-and-death situation for a community and it disrupts the smoother functioning of a country. It causes a widespread human, material, and environmental loss that makes a community incapable of facing the situation with its current resources. Disasters are a kind of tragedy because they impact and affect our lives (Paul, 2011). In contemporary literature, disasters are an unpredictable and unmanageable hazard of human life, and disaster in all forms brings sudden adversity that hampers the usual life of a society. It could be a natural or manmade catastrophe that hinders normal work life, damages property and the losses could be incurable (Carter, 2008).

\subsection{Disaster management}

Disaster management is an operational process of anticipating possible threats and exploring ways to tackle the strains caused by a disaster. It includes disaster risk anticipation, assessment, and mitigation (Khan, Vasilescu \& Khan, 2008). It is also termed as disaster crisis management (Quarantelli, 1988). It includes hazard identification, disaster preparedness, disaster response, and post-disaster management (Gerber, 2007; Collins, 2000). Disaster management also includes capacity-building interventions by a country in managing hazards (Khan \& Khan, 2008).

The definition of disaster management is not about stopping such an event when it occurs. Rather, it is about reducing the impact of these events on a company or community (Cavallo \& Noy, 2009). Disaster management covers a whole range of events, including communication failures, public disorder, terrorism, natural disasters, and artificial disasters like electric fires and industrial sabotage (Haddow, Bullock \& Coppola, 2017; Mamman, 2016). Disaster Management is defined as the preparedness of organizations in managing resources and setting responsibilities to deal with all sorts of disaster responses, relief and rehabilitation innervations, and post-disaster functions. It also covers the impact assessment of disasters and disaster preparedness activities (Perry, Lindell \& Tierney, Eds, 2001). However, government machinery at all stages, nongovernment development organizations, and community-based organizations should play an effective role before and after the occurrence of disaster and must not limit this program basing 
on the idea of post-disaster management (Khan et al., 2008; Shaw, 2003). Disaster management programs must be facilitated by efficient planning, preparedness, organizational development, effective training, information systems development, publicity, external relations, and most importantly to follow the "Total Risk Management Approach" (Hasanzadeh \& Bashiri, 2016).

\subsection{Urban Disaster Management}

Precedence of urban disaster management (UDM) is growing day by day and particularly vulnerable to poor communities living in the slump area. Urban disasters should be managed with due diligence and competencies must be developed among all stakeholders to ensure effective disaster management (Price \& Vojinovic, 2008). According to Shaw \& Sharma (2011), climate change is provoking urban disaster internally and cities must be resilient to confront the disaster situations effectively. Cities of the Asian region are prone to different forms of disasters like floods, earthquakes, landslides, and manmade disasters (Tingsanchali, 2012). Therefore, disaster management is an important element of city planning and management (Montoya, 2002). According to Rumbach (2016) decentralization of cities facilitates UDM in the area of disaster planning and governance and local authorities must be empowered in this regard. Hence, the city managers must focus on preparing the citizen to participate in disaster management activities in an orderly manner (Jha, Bloch \& Lamond, 2012) and community-based disaster risk reduction is evident in this respect. The participation of the citizen could be ensured using mobile phonebased technology to forecast and plan disaster management programs (Song \& Sun 2010, June). A consensus must be developed among the disaster management agencies and citizens for recovery activities in post-disaster crisis management (Banba \& Shaw, 2016).

\subsection{Disaster management practice in Bangladesh}

Disaster management in Bangladesh refers to the conservation of lives and property during a natural or man-made disaster (Khan, 2008). Disaster management plans are multi-layered and are planned to address issues such as floods, hurricanes, fires, mass failure of utilities, and pandemic (Tingsanchali, 2012). Bangladesh is especially vulnerable to natural disasters for its adverse climate conditions and this region is prone to frequent inversions like droughts in the northern part, floods all over the county, and cyclones in the south and south-eastern regions. Earthquakes and landslides in the hilly areas are emerging threats. Due to the vastness of the country different regions are vulnerable to different natural disasters (Rahman, 2013).

The new development approach preaches that sustainable development cannot be ensured if the mitigation of natural disasters is not included in the development process of a country (Christoplos, Mitchell \& Liljelund, 2001). According to Botha et al. (2011), the new concepts of disaster management demands sufficient investments in mitigating post-disaster challenges and concentrating on cost-effective relief and rehabilitation programs. Disaster management occupies a significant position in the policy framework of Bangladesh, as the poor people are largely affected by disaster and they are the largest population (Poncelet et al., 2010). The approach to disaster management has been projected into a National Disaster Framework of Bangladesh which subsumes institutional capacities to prevent disaster, develop prompt warning method, alleviation of disaster, the vigilance of disaster stakeholders, disaster response and disaster 
education through human resource development interventions (Khan \& Rahman, 2007). Essential resources, scopes of interventions, and government and voluntary agencies are identified and engaged at the root of managing disasters situation consistent with the roadmap (Hossain, 2012). This roadmap has been shared with all the Administrations. Respective Ministries and the Departments of the Government of Bangladesh have been advised to develop their respective roadmaps taking the national roadmap as a broad guideline (Habib, Shahidullah \& Ahmed, 2012).

\subsection{Citizen Engagement in Disaster Management}

Different mechanisms exist in the citizen engagement domain (Khaled, 2015), but simply speaking every individual of a particular country can exercise his/her constitutional rights. Citizen engagement is the involvement of people in policy formulation, design, and implementation. It allows the participation of people of all layers in a community to put their voice in the developmental program of a country (Sheedy, MacKinnon, Pitre \& Watling, 2008). It demands the motivation of the people in development and crisis management activity.

Khaled (2015) described the case of a community action forum for solving social problems, which is also an action-oriented citizen engagement model. Citizen engagement in disaster management is a democratic form that facilitates the minimization of the havoc of a disaster through the willing participation of the common people of a country (Schoch-Spana et al., 2016). It is all about citizens who are involved in disaster management policy formulation, preparation, and execution (Gonzalez, 2005). Citizen Engagement in Disaster Management demands the voluntary actions done by the community people to manage and mitigate disaster and support post-disaster development activities. It is a form of participation by the people in emergency crisis management (Rood, 2012).

\subsection{Research Gap}

There are a good number of studies on disaster management in the existing literature including Banba \& Shaw (2016), Christoplos et al. (2001), Botha et al. (2011) and many more and their contribution is limited within disaster risk management, disaster preparedness, and disaster response issues. However, most of the existing researches focused on natural disaster management. Comparatively, the emphasis given to manmade disasters like urban fire, pandemic, and waterlogging, is seen as rare. This study will attempt to fill up the gap of previous researches by discovering the facts related to the UDM of Bangladesh with special reference to Citizen Engagement.

\section{Research Methodology}

This study tried to reveal the necessity and degree of citizen engagement as a resilient intervention to the UDM program of Bangladesh. It basically focused on extracting the opportunity of citizen engagement in the UDM of Bangladesh and their limitations to this regard. Emphasizing the research objectives, the research followed the phenomenological methodology of research applying a philosophical approach as the study endeavored to interpret the experiential knowledge on citizen engagement that directly or indirectly involve in aiding the UDM programs of Bangladesh. Though it was not a hypothetical study, the research tried to 
develop theoretical knowledge based on primary and secondary data analysis and hence it might be considered as an inductive approach following phenomenology. For analyzing data, the study used the qualitative research method to identify the in-depth problems that were related to hindering the smooth conduct of citizen engagement in urban disaster management in a manner of diagnostic study.

Primary data were collected through an unstructured interview where secondary data were reviewed from the previous performance of citizen engagement for an in-depth study. Hence, the Focus Group Discussion was organized among different stakeholders and development partners of disaster management for meeting the rationale of the research. A semi-structured questionnaire was used to gather the key informant of the research by interviewing the respondents to identify the problems of citizen engagement and to suggest possible recommendations. The study faced the limitations of the shortfall of secondary data, the limited scope of collecting information from all respective stakeholders of disaster management.

Though the research endeavored to cover all major stakeholders of disaster management and the development partners engaged in disaster preparedness, response, and impact assessment activities, responsible officials from the major agencies were interviewed to gather key information. 20 Officials of Bangladesh Fire Service \& Civil Defense (FS\&CD) department, 15 officers of Bangladesh Police Force, and 10 Ward Councilors of Dhaka and Chattogram City Corporations were interviewed. All the officials of FS\&CD and Police were chosen considering their involvement in disaster response. Ward Councilors were chosen based on their persistence of the water logging problem and the density of the population. The thematic content analysis method of qualitative data analysis was used to identify the common pattern of responses given by the respondents across the data set. Familiar responses by the respondents were noted, gathered in one place, sorted, and categorized the most frequent opinions and arguments. Then those have been presented in a narrative analysis manner in the findings and discussion part.

\section{Findings and Discussion}

The findings of the study were based on the most frequent comments provided by the respondents. Common opinions on the causes and types of citizen disengagement in urban disaster response and numerous challenges faced by the disaster management personnel and officials during urban rescue operations are described in an abstract form.

\subsection{Synopsis of the findings on the issue Urban Fire Disaster Management}

Disaster management in the urban area is challenging for the key agencies involved in urban disaster management. According to the opinion of the key stakeholders of civil defense, a citizen has a diverse response to the activities of concern agencies and sometimes obstruct to different ways. Most of the time the curious mass appears in the affected area as an audience and creates crowds which seriously hampers the rescuers. Sometimes many of those crowds behave in a hostile manner and at times they become over-excited and get involved in the rescue operations without proper knowledge and hence many of them sometimes become victims of unpleasant happening and the relatives and acquaintances of victims become emotional and create panic and 
distract the rescuers. Again misdemeanors are not unusual in the affected areas who seek the opportunity of snatching and taking away the instruments of the rescuers and the victims.

\subsection{Synopsis of the findings on the issue of waterlogging}

Ward councilors of Dhaka and Chattogram City Corporation were interviewed to unfurl the situation of waterlogging problems. Respondents opined that city dwellers are responsible for blocking the drainage system by littering non-degradable wastes and uses drains and water channels for dumping the garbage. On the other hand, due to lack of proper planning of establishing residential houses, market places, and other building establishment and setting up temporary hawkers anywhere of the footpaths, illegal possession of major water channels streaming through the city areas, forceful possession of water canals of the city area and river banks by the political goons and gradual decrease of pods and other water reserves, the flow of water especially during the rainy seasons are tremendously logged and crates man-made disasters.

Disengagement of the citizen in the UDM program regarding waterlogging mostly relates to the citizens' negligence, most of the time they do it intentionally to which they have become habituated for their long time malpractices. Many respondents opined that most of the mass people don't bother the use of their common sense for the sack of their lacking proper education and awareness where many other complained the deficiency of infrastructural preparedness as the major cities are owing inadequate and very traditional waste management system and lack of vibrant governance on waste disposal are accountable for disengagement of the citizen in the UDM program regarding waterlogging.

\subsection{Synopsis of the findings on the issue of concerning dengue epidemic}

The most catastrophic pandemic (Dengue Fever) shattered the peaceful livelihood of the dwellers of the capital city Dhaka and most of the main cities of Bangladesh. Ward councilors of Dhaka and Chattogram City Corporation were interviewed to develop facts in this regard. Regarding the citizen impediment to the UDM program of the dengue epidemic, most of the respondents claimed that the citizen's careless gardening at the rooftop, balcony, and home block waters for days. Again according to many, storing freshwater in construction and other sites and carelessly throwing unused water containers and pet bottles and reluctant to take necessary medical treatment on time are the reasons. Almost all the respondents agreed to the fact that the lack of awareness of the citizen for their disengagement in the UDM program regarding the dengue epidemic.

\subsection{Summary of the findings on the issue of the COVID 19 pandemic}

Police officials of different operational levels were interviewed to understand the current challenges of citizen engagement regarding uncertain adversity of recent pandemic outbreak of the COVID 19. Most of the respondents claimed, the reasons of citizen impediment to the UDM program concerning the COVID 19 pandemic are disobedient to government instruction of home quarantine, going out of the home without any serious necessity, not bothering and maintaining the precaution of health instructions provided by the Ministry of Health, WHO and other 
concerned health authority like maintaining social distance, staying home, wearing protection gears (mask and gloves) while going out, staying away of spreading rumors via social media, involving in unplanned relief work personally, overstocking necessary items and creating a shortage of commodities in the market so that the price might not reach to peak for the shortage of stock for time being, stopping migration from and to the locked-down areas and the major cities, stopping all kinds of mass gatherings even for religious preach and obligations and so on. Again, almost all the respondents agreed anonymously to the same opinion regarding the causes of disengagement of citizens in the UDM program concerned with the COVID 19 pandemic. According to them, many citizens are intentionally neglecting the issue and some are habituated to be reluctant and most of the young generation is much curious and overexcited to be engaged as if it is an adventure to them, again many opines that a large portion of our citizen is uneducated and less aware of the engagement to the UDM program and almost impatient to sustain a crisis moment let alone pandemic.

\section{Recommendations}

The following recommendations are put forward in line with the findings above.

\subsection{Developing Disaster Preparedness Platform}

Disaster preparedness refers to measures taken to be prepared of reducing victimize of disaster. Disaster preparedness provides a platform to design effective, realistic, and well-coordinated planning reduces duplication of efforts, and increases the overall effectiveness of National Societies, households, and community members for disaster preparedness and response efforts. Public and private initiatives should be fostered to ensure citizen engagement in disaster management in a controlled way following a proactive system. As engaging citizens is a critical and challenging task, an effective control mechanism is obviously needed to bring efficiency in disaster management.

\subsection{Conducting Disaster Management Awareness Programs}

Regular awareness programs could be conducted by the local city corporation in association with all disaster management stakeholders in the residential areas. Welfare societies of each residential area and high-rise apartments could be involved in arranging such programs. Awareness programs should mainly focus on disaster risk reduction concepts and practice to reduce disaster risks through systemic efforts. It could, therefore, encompass a broad range of activities for initiating a practical approach reflecting the potential hazards of a specific area, "search conference" on community-based initiatives for disaster response and technical solutions to develop a proactive system of disaster preparedness. Apart from this, special posters and handbills on prevention, mitigation, and preparedness campaign could be distributed publicly. Special awareness programs should be arranged focusing on the duties of services of civil defense personnel regarding the citizen engagement in their activities during the time of crises. Electronic and print media should come forward to develop documentaries and supplements on disaster management activities to make the citizen conscious of crisis management. 


\subsection{Arranging Community Based Training Programs}

This training should focus on Disaster Risk Reduction and citizen role in disaster response. Disaster response training should be rehearsed on demo specifically on fire drills, fire-fighting, earthquake drills, and most importantly how to act at the time of pandemic like COVID 19. The ultimate goal of these programs is to enhance and increase the response capabilities of the local people along with the disaster-prone areas to provide the opportunity for the communities to evaluate and test its preparedness plan. The industrial, residential, and commercial areas of the city corporations should be selected and a citizen special task force could be formed to organize the training program on area-based.

\subsection{Developing Disaster Management Leadership Development Program}

Special leadership development programs could be organized for citizen special task force authorized by the government. An Emergency Team Leadership Program should be conducted by the disaster stakeholders and disaster management agencies in order to develop competence among the team leaders of the citizen. To handle the crisis of pandemic like Corona Virus, an Emergency Team Leadership Program might be conducted to enhance the effectiveness of citizens and to develop leadership quality among them which might help them to define their roles to contain the crises and act upon the instruction provided by the government agencies. The training program should focus on disaster leadership skills i.e. self-awareness and interpersonal skills, emergency technicalities, emergency operations, planning, and disaster security. Some key themes should be addressed in the program including "emotional intelligence," "situational leadership," "collaborative negotiation," "decision-making in emergencies," "team-building" and "coaching." All learning activities, discussions, and presentations should be contextualized reflecting the emergency environmental challenges, and scenarios. This program will strengthen the quality of leadership of the citizen in disaster operation and shall support their stronger coordination to the citizen and disaster management agencies and foster the development of best practice in emergency leadership and management and shall contribute to the expansion of a larger cadre of experienced citizen leadership for effective disaster preparedness and response.

\subsection{Developing a National Curriculum on Disaster Management}

Disaster Management mainly the disaster risk reduction should be systematically included in the national curriculum of primary and secondary level. The content must extend beyond the basic science of hazards and safety measures to consider prevention, mitigation, vulnerability, and resilience building. Special co-curricular activities could be organized at school and college to inspire the learners. National and international inter-school competition could be organized on disaster management to engage the future generation in disaster management activities in a systematic way. Compulsory primary firefighting training should be arranged at all levels of education.

\subsection{Forming a voluntary disaster management association}

Volunteering is generally considered an altruistic activity and is intended to improve human quality of life. In return, this activity produces a feeling of self-worth and respect instead of 
financial gain. Volunteering is also renowned for skill development, socialization, and fun. It is defined as any activity that involves spending time, unpaid, doing something for the benefits environment or someone (individuals or groups) other than, or in addition to, and close relatives. Central to this definition is the fact that volunteering must be a choice freely made by everyone. This can include formal activity undertaken through public, private, and voluntary organizations as well as informal community participation. Volunteerism engages people in tackling disaster preparedness and response challenges. It transforms the pace and nature of development. It benefits communities and the country at large. It strengthens trust, solidarity, and reciprocity of an individual publicly. It creates opportunities for participation. The nature of volunteering in Bangladesh is shifting day by day and at this moment it is mostly disorganized in regards to disaster management. In the urban area, people just help their neighbors and family members in their needs.

The study revealed how citizens are interrupting disaster response activities through the irresponsible act of volunteerism. Bangladesh must identify the scope of work and the uniqueness of volunteerism in the field of Disaster Management, especially on citizen engagement. The concept of voluntary citizen engagement could be incorporated in the mainstreaming disaster response in Bangladesh in the following ways.

Involving Bangladesh National Cadet Corps (BNCC) in Voluntary Rescue Missions. Providing them infrastructural supports to act as a first-line rescue force. Cadets should be provided Voluntary Fire Fighters Guild training at the institutional level. Trained members of the BNCC might be authorized to undertake rescue attempts independently.

Engaging the members of Rover Scouts in rescue and awareness programs. They might be trained in emergency medical support.

There must be a voluntary disaster management association in every academic institution. It should be made mandatory in all public and private medical colleges.

Every commercial, industrial, and residential area within City Corporation must have an organized unit of voluntary disaster management association reporting to local ward councilors. They should be assigned to call the agencies at the time of emergencies and bring order in the disaster-affected areas. They will be responsible to tackle any unwanted situation and make an accessible approach for the rescuers.

The members of the voluntary disaster management association will be authorized to report hazards to the concerned disaster management agencies. They could act as disaster intelligence team for the agencies and provide necessary insights into potential hazards and risks.

\section{Conclusion and Further Research Prospects}

Bangladesh is one of the disaster-prone countries in the world. With the acute limitation of resources, disaster management is extremely challenging for it and nearly impossible without the supports of different stakeholders. The Disaster Management Policy 2015 is the main foundation disaster management program of Bangladesh in taking up the Urban Resilience Projects (URP). These projects are expected to strengthen the capacity of the government agencies for emergency response and to reduce the vulnerability of urban areas. But ultimately, the success of these 
projects depends on how effectively citizens can be engaged with the total system of urban disaster management (UDM). This study tried to explore the scenario of citizen engagement in UDM activities.

The paper identified and elaborated on the impediments of citizen involvement in the disaster management program. It provided some policy prescription, or general recommendations, for stakeholders, to overcome those obstacles. However, an empirical investigation including all the stakeholders is essential to extend the study. Latest, Bangladesh is facing a lot of challenges related to the COVID 19 pandemic. It is now a turbulent situation and may go up to a terrifying level. Hence, the UDM would need an increased level of participation, collaboration, and coordination with the citizens, to contain disastrous situations like this. So extensive research work on active citizen engagement mechanisms in the UDM program will be very essential in the upcoming future.

Author Contributions: Kazi Nazmul Huda conceived the idea, and consolidated the findings; M. Jamir Uddin helped Huda in writing the paper, and Moslehuddin Khaled revised and formatted the paper for publication.

Conflict of interest: The authors declare no conflict of interest.

\section{REFERENCES}

Altay, N., \& Green III, W. G. (2006). OR/MS research in disaster operations management. European journal of operational research, 175(1), 475-493.

Banba, M., \& Shaw, R. (2016). Post-disaster Urban Recovery: 20 Years of Recovery of Kobe. In Urban Disasters and Resilience in Asia (pp. 227-243). Butterworth-Heinemann.

Botha, D., Van Niekerk, D., Wentink, G., Coetzee, C., Forbes, K., Maartens, Y., \& Raju, E. (2011). Disaster risk management status assessment at municipalities in South Africa. Report to the South Africa Local Government Association (SALGA).

Carter, W. N. (2008). Disaster management: A disaster manager's handbook.

Cavallo, E. A., \& Noy, I. (2009). The economics of natural disasters: a survey, Inter-American Development Bank.

Christoplos, I., Mitchell, J., \& Liljelund, A. (2001). Re-framing risk: The changing context of disaster mitigation and preparedness. Disasters, 25(3), 185-198.

Collins, L. R. (2000). Disaster Management and Preparedness. CRC Press.

Gerber, B. J. (2007). Disaster management in the United States: Examining key political and policy challenges. Policy Studies Journal, 35(2), 227-238.

Gonzalez, M. M. (2005). Citizen Involvement in Disaster Management. Naval Postgraduate School Monterey CA.

Habib, A., Shahidullah, M., \& Ahmed, D. (2012). The Bangladesh cyclone preparedness program. A vital component of the nation's multi-hazard early warning system. In Institutional Partnerships in Multi-Hazard Early Warning Systems (pp. 29-62). Springer, Berlin, Heidelberg.

Haddow, G. D., Bullock, J. A., \& Coppola, D. P. (2017). Introduction to emergency management. ButterworthHeinemann.

Hasanzadeh, H., \& Bashiri, M. (2016). An efficient network for disaster management: Model and solution. Applied Mathematical Modeling, 40(5-6), 3688-3702.

Hossain, M. A. (2012). Community participation in disaster management: role of social work to enhance participation. Sociology, 159, 171.

Jha, A. K., Bloch, R., \& Lamond, J. (2012). Cities and flooding: a guide to integrated urban flood risk management for the 21st century. The World Bank. 
Khaled, M. (2015). Chittagong social business center: a catalyst hub for sustainable business idea generation and management practice. Proceedings of Social Business Academia Conference, ESMT-Berlin, 3-4 November 2015.

Khaled, M. (2015). Community action forum for solving common problems. Procedia Economics and Finance (Elsevier).

Khan, H., \& Khan, A. (2008). Natural Hazards and Disaster Management in Pakistan. Munich Personal RePEc Archive, 11052. Available at https://mpra.ub.uni-muenchen.de/11052/

Khan, H., Vasilescu, L. G., \& Khan, A. (2008). Disaster management cycle-a theoretical approach. Journal of Management and Marketing, 6(1), 43-50.

Khan, M. R., \& Rahman, M. A. (2007). Partnership approach to disaster management in Bangladesh: a critical policy assessment. Natural Hazards, 41(2), 359-378.

Khan, M. S. A. (2008). Disaster preparedness for sustainable development in Bangladesh. Disaster Prevention and Management: An International Journal.

Kroll-Smith, J., Couch, J. S., \& Couch, S. R. (1991). What is a disaster? An ecological-symbolic approach to resolving the definitional debate. International Journal of Mass Emergencies and Disasters, 9(3), 355-366.

Mamman, S. N. (2016). An Evaluation of Disaster Preparedness in Industrial Buildings in Kano Metropolis. (Unpublished Master's thesis). Ahmadu Bello University, Zaria.

Mathbor, G. M. (2007). Enhancement of community preparedness for natural disasters: The role of social work in building social capital for sustainable disaster relief and management. International Social Work, 50(3), 357369.

Neubauer, G., Nowak, A., Jager, B., Kloyber, C., Flachberger, C., Foitik, G., \& Schimak, G. (2013, October). Crowd tasking-a new concept for volunteer management in disaster relief. In International Symposium on Environmental Software Systems (pp. 345-356). Springer, Berlin, Heidelberg.

Oliver-Smith, A. (1999). "What is a disaster?" anthropological Perspectives on a Persistent Question. In The angry earth (pp. 32-48). Routledge.

Pandey, B. H., \& Okazaki, K. (2005). Community-based disaster management: empowering communities to cope with disaster risks. Regional Development Dialogue, 26(2), 52.

Paul, B. K. (2011). Environmental hazards and disasters: contexts, perspectives and management. John Wiley \& Sons.

Perry, R. W., Lindell, M. K., \& Tierney, K. J. (Eds.). (2001). Facing the unexpected: Disaster preparedness and response in the United States. Joseph Henry Press.

Poncelet, A., Gemenne, F., Martiniello, M., \& Bousetta, H. (2010). A country made for disasters: environmental vulnerability and forced migration in Bangladesh. In Environment, forced migration and social vulnerability (pp. 211-222). Springer, Berlin, Heidelberg.

Price, R. K., \&Vojinovic, Z. (2008). Urban flood disaster management. Urban Water Journal, 5(3), 259-276.

Quarantelli, E. L. (1985). What is disaster? The need for clarification in definition and conceptualization in research. Disasters and Mental Health: Selected, 10, 41-73.

Quarantelli, E. L. (1988). Disaster crisis management: A summary of research findings. Journal of management studies, 25(4), 373-385.

Quarantelli, E. L. (Ed.). (2005). What is a disaster? A dozen perspectives on the question. Routledge.

Rahman, M. S. (2013). Climate change, disaster, and gender vulnerability: A study on two divisions of Bangladesh. American Journal of Human Ecology, 2(2), 72-82.

Rood, J. A. (2012). Public participation in emergency management. Dissertations and Theses. Paper 333. 10.15760/etd.333

Rumbach, A. (2016). Decentralization and small cities: Towards more effective urban disaster governance?. Habitat International, 52, 35-42.

Schoch-Spana, M., Chamberlain, A., Franco, C., Gross, J., Lam, C., Mulcahy, A., \& Usenza, C. (2006). Disease, disaster, and democracy: the public's stake in health emergency planning. Biosecurity and bioterrorism: biodefense strategy, practice, and science, 4(3), 313-319.

Shaw, R. (2003). The role of non-governmental organizations in earthquake disaster management: An Asian perspective. Regional Development Dialogue, 24(1; SEAS SPR), 117-119.

Shaw, R., \& Sharma, A. (Eds.). (2011). Climate and disaster resilience in cities. Emerald Group Publishing. 
Shaw, R., Surjan, A., \& Parvin, G. A. (2016). Urban Disasters and Approaches to Resilience. In Urban Disasters and Resilience in Asia (pp. 1-19). Butterworth-Heinemann.

Sheedy, A., MacKinnon, M. P., Pitre, S., \& Watling, J. (2008). Handbook on citizen engagement: Beyond consultation.

Song, W., \& Sun, G. (2010, June). The role of mobile volunteered geographic information in urban management. In 2010 18th International Conference on Geo-informatics (pp. 1-5). IEEE.

Tingsanchali, T. (2012). Urban Flood Disaster Management. Procedia Engineering, 32, 25-37.

Victoria, L. P. (2003). Community-based disaster management in the Philippines: making a difference in people's lives. Philippine Sociological Review, 51, 65-80.

U.N. Department of Economic \& Social Affair. (2018). World Urbanization Prospects. https://population.un.org/wup/

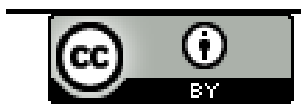

(C) 2020 by the authors. Licensee Research \& Innovation Initiative, Michigan, USA. This article is an open-access article distributed under the terms and conditions of the Creative Commons Attribution (CC-BY) license (http://creativecommons.org/licenses/by/4.0/). 